\title{
Transformative? Integrative? Troublesome? Undergraduate Student Reflections on Information Literacy Threshold Concepts
}

Rachel E. Scott

University of Memphis, rescott3@memphis.edu

\section{Recommended Citation}

Scott, R. E. (2017). Transformative? Integrative? Troublesome? Undergraduate Student Reflections on Information Literacy Threshold Concepts. Communications in Information Literacy, 11 (2), 283-301. https://doi.org/10.15760/comminfolit.2017.11.2.3

This open access Research Article is distributed under the terms of the Creative Commons AttributionNonCommercial-ShareAlike 4.0 International License (CC BY-NC-SA 4.0). All documents in PDXScholar should meet accessibility standards. If we can make this document more accessible to you, contact our team. 


\title{
Transformative? Integrative? Troublesome? Undergraduate Honors Student Reflections on Information Literacy Threshold Concepts
}

\author{
Rachel E. Scott, University of Memphis
}

Abstract

In this exploratory study the authors ask students enrolled in a credit-bearing undergraduate research methods course to rank and evaluate the troublesome, transformative, and integrative nature of the six frames currently comprising the Framework for Information Literacy for Higher Education. The results indicate that students have valid insights into threshold concept-based instruction, but may confuse the application with the theory. If practitioners are to embrace not only the frames, but also the spirit of the Framework, we must directly involve students in our teaching and research practices.

Keywords: threshold concepts; information literacy; academic libraries, instruction; undergraduate students; questionnaire

Scott, R.E. (2017). Transformative? Integrative? Troublesome? Undergraduate Honors Student Reflections on Information Literacy Threshold Concepts. Communications in Information Literacy, 11(2), 283-301.

Copyright for articles published in Communications in Information Literacy is retained by the author(s). Author(s) also extend to Communications in Information Literacy the right to redistribute this article via other scholarly resources and bibliographic databases. This extension allows the authors' copyrighted content to be included in some databases that are distributed and maintained by for-profit companies. All other rights of redistribution are licensed by Communications in Information Literacy under Creative Commons Attribution-NonCommercial-ShareAlike 4.0 International (CC BYNC-SA 4.0).

\section{[ ARTICLE ]}

Scott Transformative? Integrative? Troublesome? 


\section{Transformative? Integrative? Troublesome? Undergraduate Honors Student Reflections on Information Literacy Threshold Concepts}

\section{Introduction}

The Association of College \& Research Libraries' (ACRL) Framework for Information Literacy for Higher Education (Framework) was inspired by and based on threshold concepts, a pedagogical model developed by Meyer and Land. Threshold concepts are a discipline's foundational concepts with which learners must engage in order to cross thresholds of understanding. In a 2003 paper on threshold concepts, Meyer and Land characterized these concepts as transformative, probably irreversible, integrative, possibly often bounded, and potentially troublesome. While several experts and practitioners have evaluated the six threshold concepts (or frames) currently in place in the Framework, this exploratory study leverages Meyer and Land's definitional characteristics to ask students if and how the frames are transformative, integrative, and troublesome. Concomitant with these questions is one nagging concern: can threshold concepts function differently in a library science context than in other disciplines, or would that somehow diminish them?

The six frames at the core of the Framework were selected and vetted through an iterative process facilitated by an ACRL task force. Librarians were asked to participate in the rewriting and revising of a draft and they answered the call. Accordingly, the process drew heavily on the experience and expertise of information literacy practitioners, library and information science academics, and educational researchers. Student input has not yet directly entered into the Framework's feedback loop, despite the document's stated desire to include students' voices.

There is often a disconnect between student and teacher perspectives. This relates not only to what instructors understand they are teaching and what students actually learn, but also what content instructors and learners each perceive to be essential. The Framework calls on practitioners "to collaborate on pedagogical research and involve students themselves in that research" (2015a, para. 6). This paper is a response to the call to involve students in information literacy research. By asking students to reflect on the transformative, integrative, and troublesome nature of the threshold concepts at the foundation of the 
Framework, practitioners can better appreciate how student understandings align with those prioritized in ACRL's primary information literacy document.

\section{Research Questions}

This study poses the following questions. After one semester of frame-based instruction,

1. How do undergraduates rank, in order of difficulty and in order of transformation, the six frames?

2. How do undergraduates describe the transformative, integrative, and troublesome nature of each frame?

This paper describes an exploratory study conducted in a credit-bearing research methods class for incoming undergraduate honors program students. The librarian instructor organized the class around the frames, and at the end of the semester, conducted a voluntary and un-graded survey with both ranking and open-ended questions. The goal of the survey was to collect student impressions of the transformative, integrative, and troublesome nature of the six frames. Although the small class size means that the rankings are not generalizable, student responses to questions about the transformative, integrative, and troublesome nature of the frames reveal their perceptions of the threshold concepts selected by experts and practitioners. If the Framework is to be relevant, it must take into account student understandings of and insights into threshold concepts for information literacy.

\section{Literature Review}

All research on threshold concepts begins with the work of Meyer and Land. Since presenting this model at the Improving Student Learning Conference in Brussels in 2002, they have published and presented extensively, exploring threshold concept theory and its application in various disciplinary and learning contexts (2003 \& 2006). Their 2003 paper provided the following explanations of the definitional characteristics of threshold concepts:

- transformative - creating "a significant shift in perception"

- probably irreversible - "unlikely to be forgotten"

- integrative - "exposes the previously hidden interrelatedness of something"

- possibly often bounded - "having terminal frontiers, bordering with thresholds into new conceptual ideas"

\section{[ ARTICLE ]}


- potentially troublesome - due to ritual, inert, conceptually difficult, alien, or tacit knowledge, or troublesome language (p. 5-12).

Irreversibility and boundedness were omitted from this current study. Asking students to provide examples of a frame's irreversibility did not differ substantively from asking students how they would integrate the concept. Information literacy threshold concepts are interdisciplinary and boundedness presents problems beyond the scope of this study (Fister, 2014; Wilkinson, 2014).

The selection process of the six frames is well documented; the Framework was written by an ACRL task force with input from higher education and accreditation experts (ACRL, 2014). As outlined in the ACRL Board of Directors Action Form, the task force posted three drafts, the first in two parts, and solicited practitioner feedback via forums and hearings at national conferences, listserv messages, College $\mathcal{E}$ Research Library announcements, and social media (2015b). ACRL also used digital platforms to promote and defend the use of threshold concepts as the Framework's foundation (Townsend et al., 2015).

Townsend, Hofer, and Brunetti have published extensively on threshold concepts for information literacy (2012 \& 2016). Their 2012 qualitative survey of information literacy instructors established practitioners' identification of students' "stuck places” (p. 403). They recently collaborated with Hanick to conduct a Delphi study that engaged practitioners to select and discuss appropriate threshold concepts through four rounds of questions and evaluation (2016). However, library practitioners and library and information science academics have not universally accepted threshold concepts. Wilkinson, who initially served on the ACRL task force, provided an early critique, arguing among other points that "troublesome or transformative are agent-relative," and asking "How can probable characteristics be defining characteristics?” (2014). Barbara Fister reiterated that information literacy threshold concepts should not be discipline-specific and suggested that librarians would be unable to reach consensus in selecting or teaching threshold concepts (2014).

Librarians are not unique in their need to identify and generate consensus surrounding threshold concepts. Physiotherapy researcher Barradell listed the following as documented methods of identifying threshold concepts in various disciplines: "informal, semi-structured, phenomenographic interviews...questionnaires, surveys, short answer problems and review of old examination papers...and observation of classroom behavior" (2013, p. 269).

Although these methods have been carried out by academics, she notes that "collaboration is 
quintessential-not only with other academics but also with students. It is not enough to want to improve student learning, it is also vital to learn about that experience firsthand from those who are doing the learning" (p. 272).

In order to support their assertion that subject experts best identify threshold concepts, Townsend et al. cite various other disciplines and a few national-level information literacy documents that employed the Delphi method to identify threshold concepts (2016). Shinners-Kennedy and Fincher conducted student interviews to investigate the integrative and transformative nature of threshold concepts in computer science. Concerned by students' "hum-drum" responses and worried about the accuracy of recall and potential for hindsight bias, they switched their focus from learners to educators (2013, p. 13). Both studies provide valid evidence in support of expert identification of threshold concepts. Indeed, systematically studying student responses to threshold concepts presents many challenges and may generate results that are not reproducible. Nonetheless, inclusion of student voices, especially after the threshold concepts are initially identified, provides great insight into the usefulness and appropriateness of practitioner and expert-generated threshold concepts.

Student voice research is more prevalent in educational research than in library science literature. Cook-Sather traces interest in student voice to the 1990s and defines it as premised on the beliefs "that young people have unique perspectives on learning, teaching, and schooling; that their insights warrant not only the attention but also the responses of adults; and that they should be afforded opportunities to actively shape their education" (2006, p. 359). Seale's research on student voice in higher education reveals potential "to empower students and increase the possibility that teachers will respond to student voices," but also acknowledges a lack of documented impact due to a dearth of long-term projects to evaluate (2009, p. 33). Fielding discusses challenges to student voice research and explains the possibility of moving from speaking about or for others to speaking or working with students as co-researchers (2004).

Few studies, however, have involved students in the identification or evaluation of threshold concepts. Tucker's 2012 doctoral dissertation investigates threshold concepts for information searching and her population includes nine advanced MLIS students. OrsiniJones, an expert in student-centered threshold concepts pedagogy, has engaged English language and composition students in group and individual reflections on troublesome

\section{[ ARTICLE ]}


knowledge: "The identification of the threshold concept has therefore been entirely based on the students' voices and underpinned by a student-centered constructionist and dialogic approach" (2008, p. 216). Scott surveyed and recorded student responses to the six frames of the Framework to document that students could make sense of the language and complexity of the frames (2017). This paper similarly records students' responses to the frames, but does so in terms of Meyer and Land's threshold concept definitional criteria.

\section{Methodology}

The author invited all students enrolled in her section of an Honors Forum class (UNHP $1100)$ to participate in an exploratory study, which was approved and granted exempt status by the local institutional review board (IRB). All incoming honors students must enroll in UNHP 1100 and the enrollment is limited to 15 students per section. This one-credit hour class may be taught by faculty and staff across academic and administrative units and may focus on any topic or theme; prospective instructors are selected on the basis of a written proposal. UNHP 1100 is the only credit-bearing research methods course taught by University of Memphis librarians. For the viability of the study, students needed to study and engage with the six frames over an extended period; surveying larger groups of students after a one-shot information literacy section simply would not work.

The course syllabus, survey instrument, and link to course assignments and additional content are available in the author's personal repository: https://www.researchgate.net/ publication/316552837_Transformative_Integrative_Troublesome_Undergraduate_Honors _Student_Reflections_on_Information_Literacy_Threshold_Concepts. Class time was devoted primarily to discussions with guest speakers and final project preparations. Speakers were academics or professionals with a unique perspective on the frame in question; a documentary filmmaker spoke on "Information Creation as a Process" frame, and an attorney presented on "Information has Value." Follow-up assignments asked students to synthesize what they learned in class by responding in various ways. For example, students were instructed to visually depict their information creation process, apply a Creative Commons license to their work, and evaluate their use of citations in a previously submitted paper. The instructor labelled assignments "reflections" with the hope that students would indeed pause to consider how frames related to previous conceptual understandings. 
A survey instrument was developed and approved by the IRB; the questions were not otherwise piloted. The term "threshold concepts" was not used; instead, the frames were simply labeled "concepts." Students were first asked to rank the six frames in order of difficulty, or troublesomeness ( $1=$ easiest and $6=$ hardest). Next, they were asked to rank the frames in order of transformation ( 1 = easiest and $6=$ hardest). Then, for each frame, they were asked to describe its transformative, integrative, and troublesome nature. Instead of asking students to apply Meyer and Land's definitional criteria, to which they had had no previous exposure, the instrument asked the following:

- How has your understanding of [...] changed? Please provide 2 examples;

- How will you incorporate this understanding moving forward? Please provide 2 examples;

- Why was this concept hard to understand? Please respond in a paragraph.

Translating Meyer and Land's language into answerable questions does influence student responses; Meyer and Land's definition of "troublesome," a term not frequently used in the Mid-South, is admittedly more inclusive than "hard to understand." However, nonresponse, which is higher for open-ended than forced-choice questions, is even more likely when survey respondents cannot easily understand the question. In their guide to questionnaire development, Boynton and Greenhalgh caution that "questionnaire studies often fail to produce high quality generalizable data," but suggest that "good explanation and design improve response rates" (2004, p. 1315). Translating the definitional criteria into clear, concise, and answerable questions was undertaken with great care.

Responses to the open-ended survey questions were analyzed using summative content analysis, which begins "with identifying and quantifying certain words or content in text with the purpose of understanding the contextual use of the words or content" (Hsieh \& Shannon, 2005, p. 1283). Going beyond mere usage counts, this naturalistic analysis identifies themes and patterns to explore deeper meaning. The results section provides details of the themes that arose in the student responses in addition to their frequency. Direct quotations contextualize identified themes and patterns. 


\section{Results}

Thirteen of 14 students responded appropriately by ranking the frames as requested. One student did not assign a unique rank, but rather assigned all fours or fives. This student's rankings were omitted.

Thirteen students ranked in order of difficulty each of the six frames (see Table 1). According to the ranking, the three most troublesome frames were "Scholarship as Conversation," "Searching as Strategic Exploration," and "Authority is Constructed and Contextual." The remaining three frames were consistently ranked as less difficult concepts. Some students struggled to understand the relevance of the conversation metaphor to the frame "Scholarship as Conversation." Other students suggested that this concept was initially difficult as an abstraction, but explained that they later gained understanding through application of the theory. Some students discussed the "Searching as Strategic Exploration" assignment instead of the concept. Accordingly, the perceived difficulty may have been due to the amount of work required to complete that assignment. Student responses reveal that "Authority is Constructed and Contextual" was perceived as troublesome because of the work entailed to establish the authority of a source; students indicated that the concept was less difficult than it was new and work-intensive.

Table 1: Student rankings of perceived difficulty of frames

\begin{tabular}{|l|l|l|l|}
\hline Rank in order of difficulty, 1-6 & Average & Median & Mode \\
\hline Authority is constructed/contextual & 4 & 5 & 6 \\
\hline Information creation as a process & 2.92 & 2 & 1 \\
\hline Information has value & 2.46 & 3 & 3 \\
\hline Research as inquiry & 2.92 & 3 & 2 \\
\hline Scholarship as conversation & 4.54 & 5 & 3 \\
\hline Searching as strategic exploration & 4.15 & 5 & 5 \\
\hline
\end{tabular}

Based on the ranking, only "Research as Inquiry" stood apart as transformative (see Table 2). Most student responses to this frame used language indicating a change of understanding or approach. For example, one student wrote, "This section really reshaped the way I viewed research. I learned that researching with specific questions in mind rather than researching with the sole intention of gathering data makes the process much easier and more enlightening." "Authority is Constructed and Contextual” was ranked the least 
transformative, which may be surprising considering the number of student responses that indicated change. Indeed, all students provided two examples of how their understanding of the topic had changed, and three indicated that the concept was entirely new.

More interesting, especially given the small sample size, are the themes identified in the responses to open-ended questions. The following sections will include summative content analysis of student answers to the survey's open-ended questions.

Table 2: Student rankings of perceived transformative nature of Frames

\begin{tabular}{|l|l|l|l|}
\hline Rank in order of transformation, 1-6 & Average & \multicolumn{1}{c|}{ Median } & Mode \\
\hline Authority is constructed/contextual & 2.77 & 2 & 1 \\
\hline Information creation as a process & 3.85 & 4 & 2 \\
\hline Information has value & 3.38 & 3 & 1 \\
\hline Research as inquiry & 4.31 & 5 & 5 \\
\hline Scholarship as conversation & 3.15 & 3 & 3 \\
\hline Searching as strategic exploration & 3.54 & 3 & 2 \\
\hline
\end{tabular}

\section{Authority is Constructed and Contextual}

Students indicated that this frame opened their eyes not only to the quality of sources, but also their variety and appropriate use. Students used words associated with authoritativeness (e.g., truthful, legitimacy, authoritative, scholarly, good-quality, factual, specific URL domain types) to discuss both how this frame transformed their understanding and how they will integrate it into future research endeavors. Not surprisingly, most students directly evoked the author (e.g., creator, producer, author, source) to discuss how their authority could be established in relation to both the transformation and integration of this frame. Many used critical language (e.g., evaluate, biased, not trust, critically) with respect to the author. Students wanted to know about who created information, and how and why the author has done so.

Students identified several techniques for integrating this frame into their research processes. Some explicitly related selecting authoritative sources to documenting their understanding. Respondents indicated the importance of not only evaluating the authority of the author, but also reading and understanding the content itself. Several students used process or time-related phrases (e.g., do more research, use my time, read through all 
contextual evidence, step back and check myself, ask more questions) to indicate their intention to dedicate more time for evaluation of sources in the research process. For instance, one student responded as follows: "Instead of just picking the first source I find, evaluate if it will actually be helpful [and] how the author presents him/herself and the information."

Is this frame troublesome? Four students indicated that it was not difficult or that it was relatively easy. Several students identified judging the authority of sources as the hardest part and provided further clarification as to why. One student said that it is "because the concept of an authoritative source varies based on [the] individual." A few indicated that source evaluation was new, and one student was not certain "if I'm just settling for info." The biggest challenge for students seemed to be investing the time and effort to do the necessary work. An awareness of the availability of more authoritative sources means that students have to option to choose between the first available source or more authoritative sources, but some students indicated lingering discomfort with source evaluation. Only one student indicated struggling with the terms "constructed and contextual" in this frame, but studying the content in the class helped him/her cross the initial barrier of the language.

\section{Information Creation as a Process}

Students ranked this frame as the second most transformative. Their responses to the openended question also demonstrated several ways in which their thinking about information creation processes changed over the course of the semester. All students provided two examples of ways in which their understanding had changed and several themes emerged. Eight students indicated that attention to the process positively affects the information produced. One student commented, "Background work is actually important and shapes the research." Five students acknowledged that different projects require different processes, and one highlighted the role of imagination in these processes: "It requires creativity just as much as it requires accurate information." Three students mentioned the quality of information sources, and three remarked on the time and focus essential to information creation processes.

Students identified several ways in which they plan to integrate this frame into their research practices. The most frequently cited plan was to organize, creatively conceive, and visually depict their research or information creation processes. Three respondents used language indicating enhanced self-awareness, such as, "figure out my own process to writing 
papers" and "know my limitations." Three students also highlighted planning for the laborious and iterative nature of information creation, and three students indicated a need to enhance their "information gathering" and planned to consult library platforms or increase the diversity of sources. One student responded enthusiastically, "I will use the online catalogs / special collections / UM Libraries to better my work / give it support."

Four students indicated this frame was relatively easy, and two did not respond. As with the other frames, students described "Information Creation as a Process" as time and workintensive. Such responses suggest that students struggled with the application, but not necessarily the concept. Those who did find this concept troublesome seemed to be responding to the break from their typical information creation processes. Identifying possible steps in the information creation process and hearing in a class meeting how a documentary filmmaker characterized his information creation process was new to many students. One student wrote, "This concept was difficult to grasp because it's hard to initially get creative with something that appears as daunting as research. As the class progressed, it gradually became familiar and fun." Introducing complexity and creativity to processes that students previously understood as fixed was challenging conceptually and in application.

\section{Information Has Value}

According to student rankings, this was among the least transformative of the frames. Nonetheless, most students identified two ways in which it transformed their thinking. Studying this frame helped students understand their own power and that of others' over their creations. Related to this was the importance of valuing other's work by properly citing it, which three students suggested. Three students expanded their understanding of the economic value of and barriers to information. One of these respondents suggested, "Information should be carefully valued [and] you must think of what the provider of the information had to do to obtain it." Two students made explicit the privilege that their university status grants them. Many students simply listed or described the variety of values that information may hold.

Most respondents were able to identify at least two ways in which they will integrate new understandings of this frame; almost all indicated that they would now cite everything, even if they would not have previously done so. Their responses indicate an enhanced respect for authors and citation. One responded humorously, "Allows me to pay respect to the OG's of the information." Responding in such colorful and authentic language suggests an 
appreciation of the concept beyond parroting the instructor. Beyond citing sources, three students indicated a need to better understand them. Five students indicated a desire to use their new understanding to protect their own work. Three described how they could show gratitude for their information privilege. Two respondents reported that they would share newfound knowledge of library databases and collections, which demonstrates interest and familiarity.

Students did not seem to find this frame troublesome. Three did not respond to question of why the frame was difficult, and six reported that it was not difficult. Three students responded not to the difficulty of the concept, but to the associated assignment of selecting, creating, and embedding a Creative Commons (CC) license. Only one student seemed to grapple appropriately with the bigger ideas, responding that "This concept was hard to understand because the broadness of the word 'value.' [I] did not understand what value information had toward research explicitly." Focusing on the assigned task of creating and embedding a CC license for their own work was supposed to help the class think broadly about information ownership, appropriation, and value. Perhaps the logistical challenges of the assignment served as a distraction from conceptual engagement.

\section{Research as Inquiry}

In what was ranked the most transformative frame, most students used language suggesting the importance, value, or even necessity of asking and being open to questions throughout the research process. Learning about this concept reiterated the ongoing nature of research for five students, including one who indicated, "I realized that even after your research is done, you can still find new questions and answers." Most student responses to the question of how they will integrate this frame had to do with asking questions. Students listed several strategies, including not being afraid of asking "dumb" questions, asking more questions, understanding that some questions may not be immediately or entirely answerable, breaking down big questions into smaller, answerable questions, and seeking out answers in reputable sources. Several students noted the importance of allowing inquiry to be the impetus for research.

Students did not rank this frame among the more troublesome; however, several provided reasons why it was challenging. One student did not respond and three suggested it was not difficult. Those suggesting it was not difficult reported that the concept was not new. However, a few respondents indicated the concept was indeed new, and eight noted that the 
application posed challenges. One wrote, "this concept was new to me since I had always thought that questions were questions." Another indicated, "It was hard to take my questions and break them down to find the best way of asking in order to produce the best answer. It was also difficult trying to find out which research methods best suited me." One student struggled with the concept that not all questions are answerable. This frame in particular overlaps with compositional studies and presents concepts to which many students are exposed in English and writing classes. Despite any previous exposure, students perceived this frame as the most transformative.

\section{Scholarship as Conversation}

Although student rankings did not suggest that this frame was transformative, all students responded with at least one example of how their understanding of it had changed. Most students used language suggesting interactivity between multiple parties (e.g., author/reader, scholar/scholar, researcher/peers, self/others). Students highlighted both literal and metaphorical meanings of the frame. Three identified some potential barriers to participation. One mentioned domain knowledge as a barrier: "You have to have some type of familiarity with the topic to 'enter the conversation." Four students implied that this frame opened their eyes to the complexity of scholarship. One of these students expressed his/her understanding accordingly: "Scholarship is not an attempt to find an answer to something specific; it is more along the lines of filling [in] the bigger picture."

Beyond citing sources, students presented several unique ideas for how they might integrate this frame. Some responses were vague, but most followed-up with specific ideas. A few mentioned changing their reading practices, by engaging more actively or critically with the text. One student indicated an intention to physically join conversations: "I will go to more venues (i.e., presentations) in order to discuss / listen to discussion over a topic." Another mentioned acknowledging dissenting information: "I will not be afraid to use information from others when presenting mine (agreeing and conflicting info)." One student suggested integrating the frame into his/her writing: “...allow for more dialogue between reader and author...acting as though the reader and myself are in the same room.” Two students reported they will be more inclusive in their approaches. One student highlighted seeking out the disenfranchised: "Always listen to those who are excluded from the conversation."

Although students ranked this frame as the most troublesome, four did not explain why or how. Several responses indicated that, conceptually, this was challenging. One noted that "It

\section{[ ARTICLE ]}


was ... especially hard for me to find the connection between scholarship and conversation." Two students suggested that the concept made more sense in application or after studying course materials. Two respondents indicated it was challenging because it forced them to reconsider research and information. One characterized information as fixed: "I thought most information was immovable [...] it made it challenging to have conversation with other information." Only two students said that it was not troublesome, but made them call into question using sources without understanding. The desire to engage with and understand sources relies on an understanding of the conceptual importance.

\section{Searching as Strategic Exploration}

Students' understanding of this frame was transformed along several expected lines. Several replied that they now know there is no single search platform or search engine that can find all information. Several students learned where they search depends on what they are hoping to find, and that not all information has been published. Many respondents used library-specific terminology to indicate a new understanding of catalogs, databases, and discovery. One reported, "I was introduced to the catalogs and databases that Memphis offers. I realized that information is found in so many different systems and organized." Seven students used terms like scholarly, reliability, trustworthy, biased, good, and perspective to suggest a link between source evaluation and searching. Four respondents also used time-related words to indicate that strategic does not necessarily equate to efficient, and two reported a need for flexibility.

Students responded they will integrate what they have learned by not relying on Google. Eight respondents specifically mentioned library resources or collections. As an example, one noted specific platforms and resources: "I will use databases in the future for more specific topics. For finding primary sources I will use the libraries quick search or use special collections." Allocating more time for the research process was specified by four students. This was ranked among the more troublesome frames, and the survey responses echoed the ranking. Three students did not respond to the question, and who responded that it was not difficult quickly and amusingly contradicted him/herself: "This one wasn't hard to understand. It was one that I didn't like, however. I hate it when I can't find information quickly." This student acknowledged the time entailed in research and unwittingly provided an example of the conflation of application and theory. Instead of addressing the complexity of the topic, the student explained why she/he did not want to apply it. Another student 
suggested that information overload-the variety of sources to read and platforms to search-was the hardest part. A few suggested that the frustration and failed searches made this frame difficult. Another respondent effectively summarized several facets of this frame's troublesomeness: "This concept was hard because it forced you to explore deeper into what you thought you already knew, as well as staying motivated, open-minded, strategic, and focused throughout your exploration."

\section{Limitations}

The open-ended, written questionnaire format has several limitations. By asking students to provide examples of how their understanding has changed, the author implies that it should have. However, without soliciting examples, the responses could not have been counted and compared. The format also lacks interactivity. Unlike an interview format, in which the researcher can ask for clarification, the survey responses must be accepted as given. This proved problematic: for example, when responses to the question "Why was this concept hard to understand?" focused not on the frame as a threshold concept but rather on the specific class assignment associated with it. This may have been improved with input from piloting the questions or with explicit instructions to focus on the theory, but ignoring any application of the theory would likely have proven difficult. One characteristic of an expert is the ability to discuss theories in abstraction; learners closer to the novice end of the novice-to-expert continuum are less comfortable with abstraction may instead point to experiences or concrete examples of application (Hinds, Patterson, \& Pfeffer, 2001).

The small class size renders the rankings ungeneralizable. Additionally, this study's population of incoming honors students is not representative of the institution-wide undergraduate student body. The group included 13 first-year students and one sophomore who had all been recently admitted to the Honors Program. As shown by Fabbi (2015), incoming undergraduates with honors-level course experience are likely to achieve enhanced information literacy competency scores. It is also possible that study participants also had high school experience with honors courses and were well-situated to demonstrate a higher level of information literacy competency than their non-honors peers.

Despite these limitations, the results provide valuable insights into the perceived transformative, integrative, and troublesome nature of the six frames. The themes identified and the students' input provide useful feedback to the instructor and to other library practitioners interested in incorporating student understandings into work. 


\section{Conclusion}

The goal of this study was to explore student understandings of the six frames currently comprising the Framework for Information Literacy for Higher Education. By asking students to rank and explain how and if the frames are transformative, integrative, or troublesome, librarians gain some insight into students' relative perceptions. The analysis of student responses reveals several examples of their perceptions of the transformative, integrative, and troublesome nature of the information literacy threshold concepts in the Framework. Survey responses demonstrate that students have useful insights into threshold conceptbased instruction that might be leveraged to enrich instructional design and pedagogy and to enhance practitioner awareness. For example, student responses forced the librarian instructor to acknowledge how skills-based instruction can potentially preclude, and not necessarily compliment, larger concept recognition and understanding.

Of particular note, students did not perceive most of the selected frames to be troublesome. This finding might be attributed to student hubris or a superficial understanding of the frames. The Framework acknowledges a spectrum of learners from novice to expert; as information literacy novices, the study subjects might have demonstrated the DunningKruger Effect by overestimating their comprehension (1999). Their responses nonetheless indicate that most frames appear to be accessible to students. If this finding holds true, can librarians accept that the expert and practitioner-selected frames do not meet the definitional criteria of being troublesome? If librarians accept that these frames are not bounded, can they also accept-pending more evidence-that these frames are not troublesome in the ways in which threshold concepts in the disciplines are? If anecdotal evidence and research findings continue to suggest ways in which information literacy frames are different from threshold concepts in other disciplines, at what point do the frames function not as threshold concepts but concepts prioritized by librarians?

If practitioners are to embrace the frames and the spirit of the Framework, they must involve students in their teaching and research practices. Practitioners can collaborate with institutional partners, such as first-year writing faculty, to teach and assess student understanding of threshold concepts at the programmatic level, or partner directly with students to interrogate these questions as an undergraduate research opportunity. Student voice research has the potential to profoundly change the relationship of library instructor and students. As librarians seek out and value student voices, they work to ensure that student input will filter into future revisions of the Framework. 


\section{References}

Association of College \& Research Libraries. (2014, Nov. 12). 3rd draft: Framework for information literacy for higher education. Retrieved from http://acrl.ala.org/ilstandards/ wp-content/uploads/2014/11/Framework-for-IL-for-HE-draft-3.pdf.

Association of College \& Research Libraries. (2015a). Framework for information literacy for higher education. Retrieved from http://www.ala.org/acrl/standards/ilframework.

Association of College \& Research Libraries. (2015b, Jan. 16) Board of Directors Action Form: ACRL MW15 Doc 4.0. Retrieved from http://acrl.ala.org/ilstandards/wpco.

Barradell, S. (2013). The identification of threshold concepts: A review of theoretical complexities and methodological challenges. Higher Education, 65(2), 265-276. http://dx.doi.org/10.1007/s10734-012-9542-3.

Boynton, P. M., \& Greenhalgh, T. (2004). Selecting, designing, and developing your questionnaire. BMJ, 328, 1312-1315. http://dx.doi.org/10.1136/bmj.328.7451.1312.

Cook-Sather, A. (2006). Sound, presence, and power: Student voice in educational research and reform. Curriculum Inquiry, 36(4), 359-390. http://dx.doi.org/10.1111/j.1467873X.2006.00363.X.

Fabbi, J. L. (2015). Fortifying the pipeline: A quantitative exploration of high school factors impacting the information literacy of first-year college students. College $\mathcal{E}$ Research Libraries, 76(1), 31-42. http://dx.doi.org/10.5860/crl.76.1.31.

Fielding, M. (2004). Transformative approaches to student voice: Theoretical underpinnings, recalcitrant realities. British Educational Research Journal, 30(2), 295-311. http://dx.doi.org/10.1080/0141192042000195236

Fister, B. (2014, May 22). Crossing thresholds and learning in libraries.” Library Babel Fish. Inside Higher Ed, Retrieved from https://www.insidehighered.com/blogs/library-babelfish/crossing-thresholds-and-learning-libraries\#sthash.AsO9Tifm.dpbs.

Hinds, P. J., Patterson, M., \& Pfeffer, J. (2001). Bothered by abstraction: The effect of expertise on knowledge transfer and subsequent novice performance. Journal of applied psychology, 86(6), 1232-1243.

\section{[ ARTICLE ]}


Hofer, A.R., Townsend, L., \& Brunetti, K. (2012). Troublesome concepts and information literacy: Investigating threshold concepts for IL instruction. portal: Libraries in the Academy, 12(2), 387-405. Retrieved from http://pdxscholar.library.pdx.edu/ulib_fac/60/.

Hsieh, H.F., \& Shannon, S. E. (2005). Three approaches to qualitative content analysis. Qualitative Health Research, 15(9), 1277-1288. http://dx.doi.org/10.1177/ 1049732305276687.

Kruger, J. \& Dunning, D. (1999). Unskilled and unaware of it: How difficulties in recognizing one's own incompetence lead to inflated self-assessments. Journal of Personality and Social Psychology, 77(6), 1121-1134.

Meyer, E. \& Land, R. (2002.) “Threshold Concepts and Troublesome Knowledge.” Presented at Improving Student Learning conference. https://www.brookes.ac.uk/OCSLD/ Conferences/Improving-Student-Learning-conference/2002/Papers/Symposia-4/.

Meyer, J., \& Land, R. (2003). Threshold concepts and troublesome knowledge: Linkages to ways of thinking and practising within the disciplines. (ETL Project Occasional Report 4) Edinburgh: University of Edinburgh.

Orsini-Jones, M. (2008). Troublesome language knowledge: identifying threshold concepts in grammar learning. In R. Land, J. Meyer, \& J. Smith (Eds.), Threshold concepts within the disciplines (pp. 213-226). Rotterdam: Sense Publishers.

Scott, R. E. (2017). Part 1. If we frame it, they will respond: Undergraduate student responses to the Framework for information literacy for higher education. The Reference Librarian, 58(1),1-18. http://dx.doi.org//10.1080/02763877.2016.1196470.

Seale, J. (2009). Doing student voice work in higher education: An exploration of the value of participatory methods. British Educational Research Journal, 36(6): 995-1015. http://dx.doi.org/10.1080/01411920903342038.

Shinners-Kennedy, D., \& Fincher, S. A. (2013). Identifying threshold concepts: From dead end to a new direction. Proceedings of the 9th annual international ACM conference on international computing education research. http://dx.doi.org/10.1145/2493394.2493396.

Townsend, L., Lu, S., Hofer, A., \& Brunetti, K. (30 Jan. 2015). What's the matter with threshold concepts? [Blog post]. ACRlog. Retrieved from http://acrlog.org/2015/01/30/ whats-the-matter-with-threshold-concepts/. 
Townsend, L., Hofer, A., Lin Hanick, S., \& Brunetti, K. (2016). Identifying threshold concepts for information literacy: A Delphi Study. Communications in Information Literacy, 10(1).

Tucker, V. (2012). Acquiring search expertise: Learning experiences and threshold concepts [Doctoral dissertation]. Queensland University of Technology, Brisbane, Retrieved from http://eprints.qut.edu.au/63652/1/Virginia_Tucker_Thesis.pdf.

Wilkinson, L. (2014, May 22). The problem with threshold concepts [Blog post]. Sense and Reference. Retrieved from https://senseandreference.wordpress.com/2014/06/19/theproblem-with-threshold-concepts/. 